\title{
Impact of Bullying on Psychosocial Adjustment of School-Aged Children in Nigeria Olabiyi, O.B ${ }^{1}$
}

\begin{abstract}
Bullying according to many studies and researches has been seen to have both social and psychological effects on the victims. In light of the foregoing, this study examined the impact of bullying on psychosocial adjustment of school-aged children in Nigeria sampling Education District II of Lagos State. The district comprised of secondary schools in the following zones; Shomolu Local Government Area, Kosofe Local Government Area, and Ikorodu Local Government Area respectively. Using stratified random sampling technique, 270 respondents were randomly selected as sample for this study. The research instrument, a self-constructed questionnaire titled; Impact of Bullying on Psychosocial Adjustment Questionnaire (IBPSAQ) was administered to the respondents. A descriptive research design was adopted. A total of four research questions and hypotheses were formulated and tested at 0.05 level of significance using Chi-Square. The findings revealed that bullying has significant impact on students' anxiety and peer isolation. Findings however reflected that bullying does not have significant impact on student's school absenteeism and possession of weapon. In the light of the findings reported, the researcher made the following recommendations: The schools and home should work in synergy to collaboratively instill good values in their children/students. The school should embrace counselling services to help the psychosocial wellbeing of victims of bullying. The school should develop strategies to mete out punishments for any discovered bully. Victims of bullying should be encouraged by counsellors to report bullying cases to school authority as soon as it is experienced.
\end{abstract}

Keywords: Bullying, Psychosocial, Adjustment, School, Children

\footnotetext{
${ }^{1}$ Olabiyi O.B. is from Department of Educational Foundations, University of Lagos, Nigeria.
} 


\section{Introduction}

The school is an establishment responsible for the formal education of the citizens of any country. Students acquire relevant knowledge, values and skills for useful living within the society. However, while in school students socialize with one another and interact in groups to engage in learning exercises. Nonetheless; Tapia, Fraijo, Corral, Garza and Moreno (2020) establishes that students cannot adequately develop, socially, intellectually, emotionally and physically if they do not have the right perception of the school environment and if they do not conceive the school as a friendly, safe and secure institution of learning. However, consistent with Fajoju (2009) who opined that only few students can adjust harmoniously while socializing with their school mates without experiencing violence and one form of bully tendencies or the other. Although the objectives of schooling are primarily academic in nature, Ionut (2011) opines that schools likewise are agents of socialization that not only teach subject based knowledge and life skills only, they also acquire social adjustment skills through socialization with their peers, teachers, and faculty members. The school being a social institution hence paves way for interaction between students. This interaction however sometimes becomes complex and certain delinquent behavior begin to surface like bullying. It therefore becomes of great importance for students to be equipped psychologically and socially about the tendency of bullying behavior that could emanate as a result of their relationship and interaction with their peers in class. Bullying in schools has evolved to becoming a problem with many negative consequences for the overall school climate and disrupting learning process and hampering the safety of learners (Kutsyuruba, Klinger and Hussain, 2015).

The published book "Aggression within the Schools" in 1978 by Olweus consequently lead a growing interest within the area of bullying. Findings by Olweus suggests that a student is being a victim of bullying if exposed continuously and repeatedly over time to negative action from one or more students, bullying hence often possess the attributes of an existing imbalance of power and aggressive behaviors repeated over time. Bullying has since then been established as a peer relation characterized by the imbalance of power between the parties involved, by the intentionality and repetitiveness of aggressive acts. Bullying is often attributed to psychological verbal, or physical abuse found in hitting or name-calling, destruction of victims properties, isolation from group, extortion, etc. The prevalence of bullying in schools in Nigeria as evident by 
the Federal Ministry of Education's national survey in (2007) which informed that physical and psychological violence including social denigration were common place in Nigerian schools suggests a psychosocial threat on school-aged children adjustment. In light of the forgoing, this study sort to examine the impact of bullying on psychosocial adjustment of school-aged children in Nigeria.

\section{Statement of the Problem}

The school as a social agent is believed to be concerned about preparing a solid foundation upon which the child's future is built, this is often one among many reasons parents send their children to school. The prevalence of bullying in schools however has almost negated the important essence of schooling especially among school-aged children in Nigeria. Victims of bullying and other aggressive behaviours are reported to have a myriad of physiological, psychological and social problems which could include but are not limited to; sleep difficulties; depression; aggression; school phobia; low self-esteem; Children experiencing victimization of any kind have higher rate of developing childhood anxiety disorder; and panic disorder, when compared to their uninvolved peer. The rate of aggressive victimization among secondary school students is becoming so alarming and such a menace to the society to the extent that the school that is supposed to be a place where students feel safe and secure has unfortunately become unsafe for the children who are being victimized. This however possess some negative effect on the student's social adjustment and the psychological wellbeing likewise distorting the learning process of the schooling child. Bullying has been perceived over the years as being so commonplace in schools that it's been overlooked as a threat to children and reduced to a belief that bullying may be a developmental phase that many children and youths will experience then recover from but unfortunately not everyone gets over the trauma which accompanies bullying.

Hence deeper understanding is required regarding the impact of bullying on psychosocial adjustment of school-aged children in order to inform responsive home and school practices. Thus, this study aims to fill the gap in research literature by contributing to knowledge on impact of bullying on psycho-social adjustment of school-aged children in Nigeria and sort to proffer ways forward to curbing this behavior thereby helping to make our schools and society safe again.

\section{Research Questions}

The study addressed the following research questions: 
1. What is the impact of bullying on anxiety among school-aged children?

2. What is the impact of bullying on peer isolation among school-aged children?

3. What is the impact of bullying on school absenteeism of school-aged children?

4. What is the impact of bullying on possession of weapon by school-aged children?

\section{Research Hypothesis}

The following hypotheses were tested in the study:

1. There is no significant impact of bullying on anxiety among school-aged children.

2. There is no significant impact of bullying on peer isolation among school-aged children.

3. There is no significant impact of bullying on school absenteeism of school-aged children.

4. There is no significant impact of bullying on possession of weapon by school-aged children.

\section{Significance of the Study}

The study hopes to contribute to the body of knowledge on the impact of bullying on psychosocial adjustment of school-aged children. Data provided in the study will assist parents and school administrators in making informed decisions about protecting the kids from bullying. Additionally, this study seek to enlighten students on the likely impact of bullying on their psycho-social adjustments. This research on impact of bullying on psycho-social adjustments of students will be beneficial for the social-scientific communities and policy makers so as to reinforce student's wellbeing and provide a secure learning environment. The association between bullying behavior and other sorts of offenses underlines its importance within the design, implementation, and evaluation of intervention and prevention programs for both minor and high sorts of school violence like bullying. This study seeks to add to the body of sociological findings on the need for a safe school system devoid of bullying as this would go a long way in ensuring the child trained in the school is well equipped with the right knowledge, in the right learning environment with the right skill to fit into the larger society properly thereby reducing the rate of unskilled and unfit youths in the society today.

\section{Methodology}

This study examined the impact of bullying on psycho-social adjustment of school aged children in Nigeria. Four research questions and hypotheses were asked and formulated respectively to 
serve as a guide in the conduct of the study. The descriptive survey research design was used to conduct the study. The population for this study comprised all secondary school students in Educational District II of Lagos State. 270 secondary school students were randomly selected from the three zones under Educational District II of Lagos State, Nigeria using stratified random sampling technique. A total of 150 male and 120 female respondents were selected for this study. A structured questionnaire was constructed and administered on the respondents for data collection. The data obtained after the administration of the questionnaire were subsequently analyzed using frequency counts and percentage for the demographic information of the respondents while Chi-square was adopted for testing the hypothesis. The data were run with Statistical Package for Social-Sciences (SPSS).

\section{Reliability of the Research Instrument}

This pilot study was carried out to trial test the research instrument. The study was carried out by selecting 30 students from schools in Educational District IV of Lagos State and after two weeks, the questionnaire was re-administered on the same group of students. The research instrument (IBPSAQ) was administered on the respondents in order to determine the reliability of the instrument. The two set of scores were correlated using Pearson's Product Moment Correlation Coefficient (PPMC). The result 0.85 r-coefficient was obtained, therefore the instrument was reliable.

\begin{tabular}{|c|c|c|c|c|}
\hline Statement & No of Items & Pilot Position & Mean & S.D \\
\hline Bullying & 9 & $1^{\text {st }}$ & 3.16 & 1.17 \\
& & $2^{\text {nd }}$ & 3.15 & 1.18 \\
\hline Anxiety & 8 & $1^{\text {st }}$ & 3.18 & 1.19 \\
& & $2^{\text {nd }}$ & 3.15 & 1.18 \\
\hline Peer Isolation & 8 & $1^{\text {st }}$ & 3.12 & 1.15 \\
& & $2^{\text {nd }}$ & 3.18 & 1.19 \\
\hline Possession of & 9 & $1^{\text {st }}$ & 3.29 & 0.95 \\
Weapon & & $2^{\text {nd }}$ & 3.39 & 0.97 \\
\hline Weighted Mean & & \multicolumn{2}{|c}{0.85} & \\
\hline
\end{tabular}

0.85 r-coefficient was obtained, therefore the instrument was considered reliable. 


\section{Results and Discussion}

The results from the data collected upon field study are presented in tables and figures to ensure clarity.

\section{Demographic Description of Respondents}

This section describes demographic characteristics of the respondents using frequency counts and percentage as illustrated below:

Table 1: Gender Distribution of Respondents

\begin{tabular}{lcc}
\hline Gender & Frequency & Percentages \\
\hline Male & 150 & 56 \\
\hline Female & 120 & 44 \\
\hline Total & $\mathbf{2 7 0}$ & $\mathbf{1 0 0}$ \\
\hline
\end{tabular}

Data presented in Table 1 shows that out of two hundred and seventy (270) respondents that participated in the study, 150 (56\%) were males, while 120 (44\%) were females. From this it can be deduced that although the study sampled both gender, majority of the respondent were males.

Table 2: Age Distribution of Respondents

\begin{tabular}{lcc}
\hline Age & Frequency & Percentages \\
\hline 9 to 11 years & 100 & 37 \\
\hline 12 to 14 years & 145 & 54 \\
\hline 15 years above & 25 & 9 \\
\hline Total & $\mathbf{2 7 0}$ & $\mathbf{1 0 0}$ \\
\hline
\end{tabular}

Data presented in Table 2 shows that out of two hundred and seventy (270) respondents that participated in this study $37 \%$ of the respondents were between age 9 and 11 years, 54\% were between age 12 and 14 years while 9\% were 15 years above. 
Hypothesis 1: There is no significant impact of bullying on anxiety among school-aged children. Table 3: Chi-square Analysis showing impact of bullying on anxiety among school-aged children.

\begin{tabular}{|l|c|c|c|c|c|c|c|}
\hline Variables & $\boldsymbol{N}$ & Mean & S.D & DF & $\boldsymbol{X}^{2}$-Cal & $\boldsymbol{X}^{2}$-tab & Sig. \\
\cline { 1 - 6 } Bullying & 159 & 16.09 & 4.88 & 1 & & & \\
\cline { 1 - 6 } Anxiety & 111 & 12.16 & 11.24 & 92 & 31.69 & 9.48 & 0.05 \\
\hline Total & 270 & & & 93 & & & \\
\hline
\end{tabular}

Significant at $0.05, \mathrm{df} .=1$ and $92, \boldsymbol{X}^{2} \mathrm{cal}=31.69, \boldsymbol{X}^{2}$ tab $=9.48$

The table 3 shows that the calculated $\boldsymbol{X}^{2}$ - value 31.69 is greater than the $\boldsymbol{X}^{2}$ table value which is 9.48 given 1 and 92 degree of freedom at 0.05 level of significance. This implies that the null hypothesis which state that there is no significant impact of bullying on anxiety among schoolaged children is rejected. Therefore, bullying has a significant impact on anxiety among schoolaged children in Nigeria.

Hypothesis 2: There is no significant impact of bullying on peer isolation among school-aged children.

Table 4: Chi-square Analysis showing impact of bullying on peer isolation among schoolaged children.

\begin{tabular}{|l|c|c|c|c|c|c|c|}
\hline Variables & $\boldsymbol{N}$ & Mean & S.D & DF & $\boldsymbol{X}^{2}$-Cal & $\boldsymbol{X}^{2}$-tab & Sig. \\
\cline { 1 - 5 } Bullying & 143 & 26.55 & 4.26 & 1 & & & \\
\cline { 1 - 5 } Peer Isolation & 127 & 22.06 & 3.25 & 86 & 22.246 & 9.488 & 0.05 \\
\hline Total & 270 & & & 87 & & & \\
\hline
\end{tabular}

Significant at 0.05 , df. $=1$ and $86, X^{2}$ cal $=22.246, X^{2}$ tab $=9.488$

The table 4 shows that the calculated $\boldsymbol{X}^{2}$ - value 22.246 is greater than the $\boldsymbol{X}^{2}$ table value which is 9.488 given 1 and 86 degree of freedom at 0.05 level of significance. This implies that the null hypothesis which state that there is no significant impact of bullying on peer isolation among 
school-aged children is rejected. Therefore, bullying has a significant impact on peer isolation among school-aged children in Nigeria.

Hypothesis 3: There is no significant impact of bullying on school absenteeism of school-aged children.

Table 5: Chi-square Analysis showing impact of bullying on school absenteeism of schoolaged children.

\begin{tabular}{|l|c|c|c|c|c|c|c|}
\hline Variables & $\boldsymbol{N}$ & Mean & S.D & DF & $X^{2}$-Cal & $X^{2}$-tab & Sig. \\
\cline { 1 - 5 } Bullying & 196 & 22.58 & 3.44 & 2 & & & \\
\cline { 1 - 5 } School Absenteeism & 74 & 23.34 & 2.15 & 147 & 1.724 & 3.974 & 0.05 \\
\cline { 1 - 5 } Total & 270 & & & 149 & & & \\
\hline
\end{tabular}

Significant at 0.05 , df. $=2$ and $147, X^{2}$ cal $=1.724, X^{2}$ tab $=3.974$

The table 5 shows that the calculated $\boldsymbol{X}^{2}$ - value 1.724 is less than the $\boldsymbol{X}^{2}$ table value which is 3.974 given 2 and 147 degree of freedom at 0.05 level of significance. This implies that the null hypothesis which state that there is no significant impact of bullying on school absenteeism of school-aged children is accepted. Therefore, bullying has no significant impact on school absenteeism of school-aged children in Nigeria.

Hypothesis 4: There is no significant impact of bullying on possession of weapon by schoolaged children.

Table 6: Chi-square Analysis showing impact of bullying on possession of weapon by school-aged children.

\begin{tabular}{|l|c|c|c|c|c|c|c|}
\hline Variables & $\boldsymbol{N}$ & Mean & S.D & DF & $\boldsymbol{X}^{2}$-Cal & $\boldsymbol{X}^{2}$-tab & Sig. \\
\cline { 1 - 5 } Bullying & 214 & 22.58 & 7.93 & 2 & & & \\
\cline { 1 - 5 } Possession of Weapon & 56 & 12.16 & 10.38 & 147 & 2.59 & 5.438 & 0.05 \\
\cline { 1 - 5 } Total & 270 & & & 149 & & & \\
\hline
\end{tabular}

Significant at $0.05, \mathrm{df} .=2$ and $147, \boldsymbol{X}^{2} \mathrm{cal}=2.59, \boldsymbol{X}^{2} \mathrm{tab}=5.438$ 
The table 6 shows that the calculated $\boldsymbol{X}^{2}$ - value 2.59 is less than the $\boldsymbol{X}^{2}$ table value which is 5.438 given 2 and 147 degree of freedom at 0.05 level of significance. This implies that the null hypothesis which states that there is no significant impact of bullying on possession of weapon by school-aged children is accepted. Therefore, bullying has no significant impact on possession of weapon by school-aged children in Nigeria.

\section{Discussion of Findings}

Hypothesis one states that there is no significant influence of bullying on anxiety among schoolaged children. The findings from this study however showed clearly that anxiety disorders exists among school-aged children who have been exposed to bullying in Nigerian schools. Reports from the study indicated that most victims of bullying exhibit fear and worry even while they are in school. Loss of concentration in class was also a paramount issue expressed by participants in the study. The study also reflected that many of the victims of bullying are afraid to tell their school administrators and principals their experience because they feel telling will prompt their bully to victimize them even more. This is supported by Campbell M. (2013) who opined that there is a synergy between aggressive behavior and social anxiety. Fullchange and Furlong (2016) likewise revealed that increased frequency of victimization increases the tendencies for other constructs such as anxiety disorders and depression. Findings of Reiss and McNally (2001), further opined that being a bully victim is one of many reasons of psychopathological symptoms, and may cause the generation of anxiety sensitivity in adolescents. Consequently, Reiss and McNally's assumptions that bullying may have effects on anxiety sensitivity in adolescents was found true as revealed by this study which revealed that anxiety disorders exists among school-aged children who have been exposed to bullying in Nigeria.

Hypothesis two states that there is no significant impact of bullying on peer isolation among school-aged children in Nigeria. The findings from this study revealed however that bullying as an aggressive behavior has a significant impact on peer isolation witnessed among school-aged children in Nigeria. Report from the study found that bully victims do not make friends in school because of the denigration they often experience. Victimized participants in the study chose to isolate themselves during recess rather than socialize with their colleagues to avoid being bullied. This study also found victims of bullying being isolated because they were categorized as being 
weak, unfit and unable to defend themselves by their classmates. The foregoing is supported by Garbarino and deLara, (2003), who emphasized that peer isolation is itself a problem as victims of bullying can easily become disconnected from the moderating forces of mainstream society. The findings of Garbarino and deLara (2003), explained that peer isolation can take the form of ignoring someone, openly excluding or isolating a child, rallying other students to dislike a child and usually name calling and rumor spreading can lead to this exclusion and isolation however victims of bullying are usually faced with loneliness and depression from being isolated by their peers.

Hypothesis three states that there is no significant impact of bullying on school absenteeism of school-aged children. The findings from this study however revealed that students had remained consistent in school not just because they loved coming to school but because the decision to either attend school or not was mostly not theirs to make. Parents would often not allow their children stay back at home not minding the experiences they grapple with in school. Students themselves do not often relate their bullying experience to their parents hence they are mostly forced to be in school. This study found that students do not stay away from school just because they were bullied. The findings of this study however is contrary to the findings of the study done by Hutzell and Payne (2012) who explored rates of school absenteeism and certain locations in a school setting of students who have experienced bullying using data from the National Crime Victimization Survey: School Crime Supplement 2007, the researchers were able to examine data of 11,161 students between the ages of 12 and 18. Bullying victimization and school absenteeism were both measured using a series of questions complied by the researchers. It was found that students who experience bully victimization were more likely to exhibit avoidance and absenteeism from school. However findings from this study reveals that there is no significant impact of bullying on school absenteeism of school-aged children in Nigeria.

Hypothesis four states that there is no significant impact of bullying on possession of weapon by school-aged children. This study however revealed that students do make use of weapons in school because they were bullied nor as a means of self-defense. This study found that victims of bullying did not engage in hiding any firearm in their school bags because weapons are contrabands in schools and are prohibited substances. Parents likewise engage in routine check of their wards school items and so victims of bullying do not adopt the use of weapon in school as they are being 
thoroughly checked by their parents. The aforementioned is however contrary to the findings of Phang, Keng, and Chiang (2014), who opined that bullying victims who have been threatened or have been in a fight are more likely to bring a weapon to school than other victims and no victims. The study of Phang et al (2014), also revealed that students whose sense of safety had been violated or threatened in successively more ways had a greater propensity to carry weapons to school, with each additional risk factor further compounding this risk. They reported that victims were twice more likely to carry weapons to school than non-victims. In contrast to the findings of Phang et al (2014), this study reveals that there is no significant impact of bullying on possession of weapon by school-aged children in Nigeria.

\section{Conclusion and Recommendations}

In conclusion, bullying has become a major issue of great concern in today's society, it possesses psychosocial implications for victims of this cruel behavior. Bullying can be ameliorated by adopting many strategies considering that bullying can threaten students' psychological, social, and emotional safety at school and can negatively impact their psychosocial adjustment.

In the light of the findings reported in the study the following recommendations serves as approaches to curb bullying in schools:

- The schools and home should work in synergy to collaboratively instill good values in their children/students.

- The school should embrace counselling services to help the psychosocial wellbeing of victims of bullying.

- The school should develop strategies to mete out punishments for any discovered bully.

- Victims of bullying should be encouraged by counsellors to report bullying cases to school authority as soon as it is experienced.

\section{Sociological Implications}

Keeping schools safe spurs social and creative learning in the child and helps the child anticipate being at the school at the dawn of any new academic day. When their basic safety needs are not met, children are at risk for not feeling comfortable at school. Thus, school safety provides an opportunity for the students to explore, learn and grow. John Dewey (1909) opined that the school should be a reflection of the society. Dewey expresses that school should promote values and traits 
that are in tandem with the goals and vision of the society. Hence if we would desire a society devoid of crises and social vices such as aggression, theft, terrorism etc. then the school should strive towards a school system devoid of bullying. Education is keen on ensuring the development of the individual's abilities and the formation of a knowledgeable society as a requirement for development. The foregoing suggests that the purpose of education is to assist the personal growth of the individual and national development. This study hence seeks to add to the body of sociological findings on the need for a safe school system devoid of bullying as this would go a long way in ensuring the child trained in the school is well equipped with the right knowledge, in the right learning environment with the right skills to fit into the larger society properly thereby reducing the rate of unskilled and unfit youths in the society today.

\section{Suggestions for Further Research}

This study suggests the following areas for further research:

1. Personality and environmental correlates of bullying behavior in junior secondary schools.

2. Implications of bullying victimization of students in Higher Institutions.

\section{References}

Campbell M. (2013). Loneliness, social anxiety, and bullying victimization in young people: A literature review. Psychology and Education. 50. 1-10.

Fajoju A.S (2009) School bullying and academic performances of secondary school students in Edo State. Unpublished Doctoral Research Proposal Ambrose Alli University, Ekpoma, Nigeria.

Federal Ministry of Education. (2007). Basic and Senior Secondary Education Statistics in Nigeria, Abuja. 1-5.

Fullchange, A., \& Furlong, M. J. (2016). An Exploration of Effects of Bullying Victimization from a Complete Mental Health Perspective. SAGE Open. https://doi.org/10.1177/2158244015623593

Garbarino, J. \& Delara, E. (2003). Words Can Hurt Forever. Educational Leadership.

Hutzell. K \& Payne. A (2012). The Impact of Bullying Victimization on School Avoidance. Youth Violence and Juvenile Justice. 10. 370-385. 10.1177/1541204012438926.

Ionuţ, A. (2011). Family And School Understood As Agents Of Socialization. 
Kutsyuruba, B, Klinger, D \& Hussain, A. (2015). Relationships among school climate, school safety, and student achievement and well-being: a review of the literature. Review of Education. 3. 103-135. 10.1002/rev3.3043.

Olweus, D. (1978). Aggression in the schools. Bullies and whipping boys. Washington, D. C. Hemisphere Press.

Phang, K. C., Keng, L. S., \& Chiang, C. K. (2014). Mindful-S.T.O.P.: Mindfulness made easy for stress reduction in medical students. Education in Medicine Journal, 6(2), 48-56. doi:10.5959/eimj.v6i2.230

Reiss, S., \& McNally, R. J. (2001). Expectancy model of fear. In S. Reiss \& R. R. Bootzin (Eds.), Theoretical issues in behavior therapy (pp. 107-121). San Diego, CA: Academic Press.

Tapia F.C, Fraijo S.B, Corral V.V, Garza T.G \& Moreno B.M. (2020) School Environments and Elementary School Children's Well-Being in Northwestern Mexico. Front. Psychol. 11:510. doi: 10.3389/fpsyg.2020.00510

United States Department of Justice. National Crime Victimization Survey: School Crime Supplement, (2007). Ann Arbor, MI: Inter-university Consortium for Political and Social Research https://doi.org/10.3886/ICPSR23041.v1 